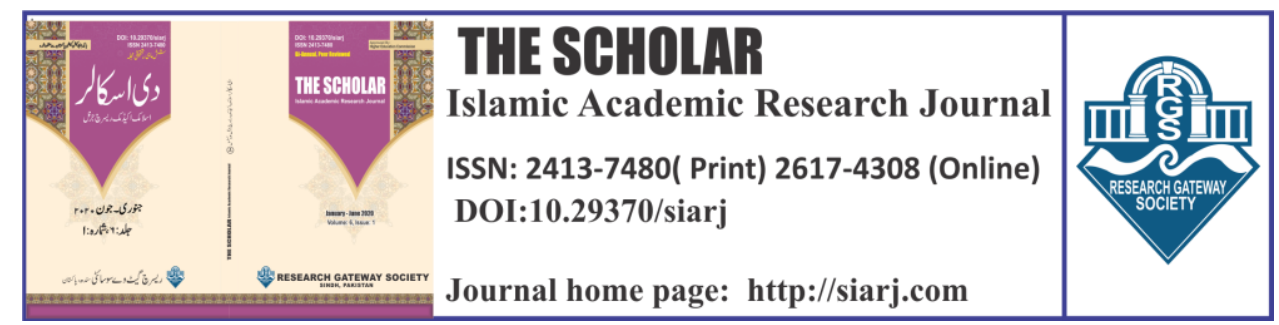

$$
\text { دراسة اختصاصية للصور القديمة والحديثة لجمع وتدوين متون الحديث }
$$

\title{
A SPECIFIC OVERVIEW OF ANCIENT AND MODERN APPROACHES TO COLLECTION AND COMPILATION THE TEXTS OF HADITH.
}

\section{1- Malik Kamran}

Lecturer, University of Gujrat, Lahore Campus, Pakistan.

Email: $\underline{\text { mktahir736@gmail.com }}$

\section{ORCID ID:}

\section{https://orcid.org/0000-0002-1602-8011}

To cite this article:

Kamran, Malik, and Abdul Rouf Zahid. "A SPECIFIC OVERVIEW OF ANCIENT AND MODERN APPROACHES TO COLLECTION AND COMPILATION THE TEXTS OF HADITH." The Scholar-Islamic Academic Research Journal 6, no. 1 (May 31, 2020): 51-67.

To link to this article: https://doi.org/10.29370/siarj/issue10ararabic3

Journal

Publisher

DOI:

URL:

License:

Journal homepage

Published online:
The Scholar Islamic Academic Research Journal Vol. 6, No. 1 || Janurary -June 2020 || P. 50-66 Research Gateway Society 10.29370/siarj/issue10ararabic3 https://doi.org/10.29370/siarj/issue10 ararabic3 Copyright c 2017 NC-SA 4.0 www.siari.com 2019-05-31

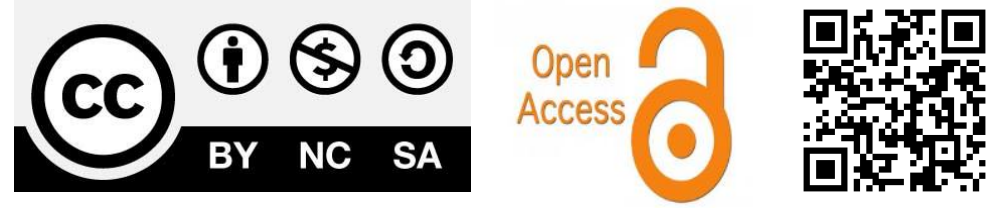




\section{دراسة اختصاصية للصور القديمة والحديثة لجمع وتدوين متون الحميث \\ A SPECIFIC OVERVIEW OF ANCIENT AND MODERN APPROACHES TO COLLECTION AND COMPILATION THE TEXTS OF HADITH.}

Malik Kamran, Abdul Rouf Zahid

\section{ABSTRACT:}

It is necessary for the views to differ from the differences of reasoning and understanding from the text. There are different opinions and attitudes among the Muslims in Islamic rules. Sometimes these views seem to contradict each other. There is an excess or less of words due to which the ruling differ in inference issues. If the Mutan of a Hadith or the whole picture of an event doesn't avail for the comparison, then the correct direction and conclusion will not be possible in the derived issues. Attempts have been made in different period of space accumulation to the best of one's ability and compile complete texts for the scholars and the scholars of Ummah which made it easier to extract problems and rules. The following article has been presented a study of different forms of editing texts in four stages.

KEYWORDS: Islamic rules، Conclusion، Text of hadith, ancient modern approaches

$$
\text { الكلمات المفتاحية: أحكام الشريعة ، الخاتمة ، متون الحديث، صور القديمة }
$$

$$
\begin{aligned}
& \text { بالنسبة لرواية السنة ، اتخذ المحدثون أسلوبا خاصا في رواية الحديث ، وأفم يجمعون عموما } \\
& \text { كل الأحاديث والأخبار التي تتوافق هدي النبي هناك أحداث خاصة تتعلق بالعصر. هذا } \\
& \text { العمل هو بالضبط نفس عمل شرطة التحقيق أو المحكمة مع شهادة العديد من الشهادات }
\end{aligned}
$$


لتأكيد أو وصف حدث أو جريمة - لابد أن تكون مختلفة عن الإيديولوجية وفهم الاختلافات.هناك الآراء والإتحاهات المختلفة في أحكام الشريعة الإسلامية بين المسلمين

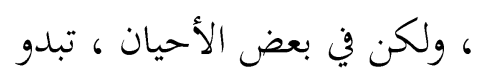

هذه الأفكار متعارضة مع بعضها البعض ، أحد أنواع الاختلافات هو نقص كلمات أو زيادة في نص الحديث ، ويرجع ذلك إلى وجود اختلاف في تفسير بعض الأحاديث وبهذ السبب يختلف الحكم لوقت الاستخراج من الأحكام. إذا كانت الصورة بأكملها من العبارة أو الحدث غير متوافق ، فلايتم حل الاتحاه الصحيح والنتيجة في أخذ المسائل .لذ الوجه لقد حاولوا المحدثون جع المتون في مكان واحد في الفترات المختلفة بقدرتم ويترتب نصوص الكاملة للمحقيقن و العلماء و جعلوا الأمر أسهل بالنسبة للذين جاءوا لاحقا-في دور الاول جمع المحدثون متون الحديث بالأسنادو يكتبون الكتب علي هذا الفن - وفي دور الثاني يجمع متون الحديث بحذف المكررات و وفي مرحلة الثالثة يتم أجزاء متون الحديث علي نطاق محدود ، وفي المرحلة الرابعة والأخيرة ، تم تنفيذ ترتيبات عرضية من لمن خلال جمع جميع جوانب الحدث أو الحديث. حين تقدم دراسة أساسية للخطوات التي اتخذتا في المراحل المذكورة في جمع المتون . أهمية لجمع متون الحديث :

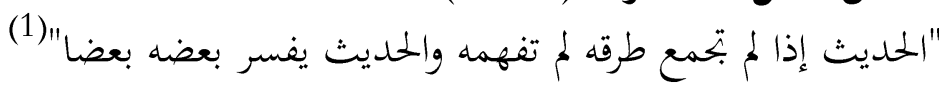

$$
\text { يقول أحمد بن حنبل عليه الرحمة(241هـ) : }
$$

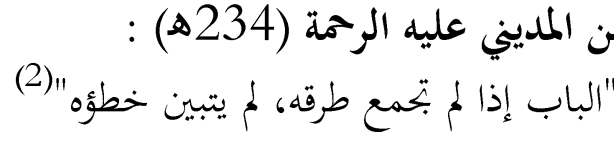

${ }^{1}$ Ahmad bin Ali Al-Khatib Al-Baghdadi, Al-Jami 'Lakhlaq Al-Rawi wa Adab Al-Sam'imuktba almarif alriaz,vol2,p312

${ }^{2}$ Uthman bin Abdul Rahman Ibn Al-Salah, Muqaddama Ibn Al-Salah de Nooruddin Attar,darulfikar , barout,1406AH,p.91 


\section{يقول ابراهيم بن سعيد الجوهري عليه الرحمة (244ه) :}

(3)"

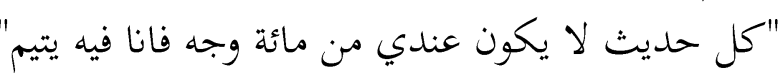

(4)

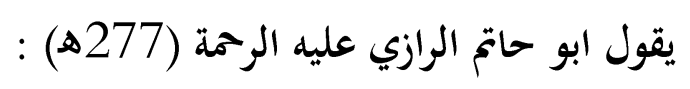

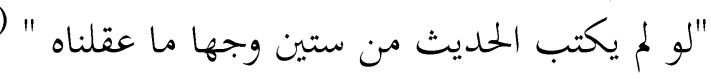

$$
\text { وبمثله يقول في موضع آخر: }
$$

"ما رأيت على وجه الأرض من من اخجسن صناعة السنن ويحفظ ألفاظها

الصحاح ويقوم بزيادة كل لفظةزاد ها في الخبر ثقة حتى كأن السنن كلها

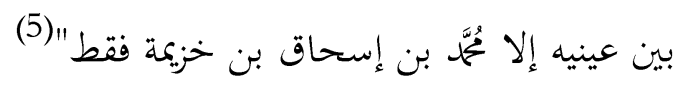

$$
\text { يقول ابراهيم الحربي عليه الرحمة (285هـ): }
$$

"سمعت المسيبي، يقول: رأينا الواقدي يوما جالسا إلى أسطوانة في

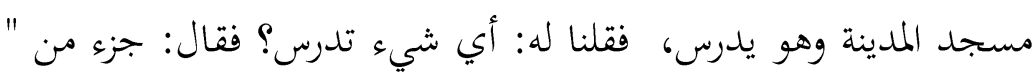

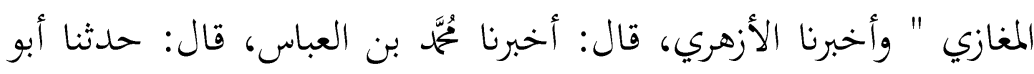

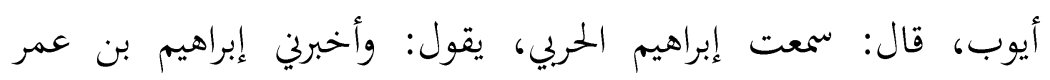

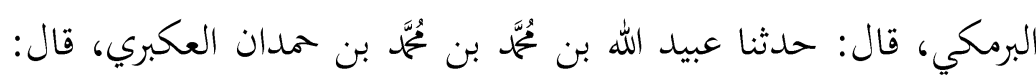

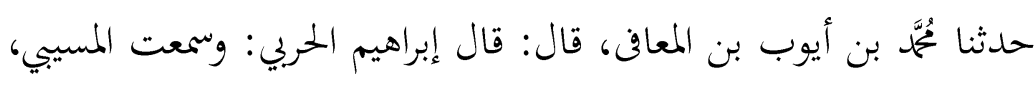

يقول: قلنا للواقدي: هذا الذي بتمعالرجال، تقول: حدثنا فلان وفلان

وجئت بمتن واحد، لو حدثتنا بجديث كل رجل على حدة. قال: يطول.

فقلنا له: قد رضينا. قال: فغاب عنا جمعة، ثم جاءنا بغزوة أحد عشرين

${ }^{3}$ Muhammad ibn Ahmad al-Dhahabi, Tazkira al-Hifaz, Dar al-Kitab alUlamiya, Beirut, 1419 AH, vol. 2, p. 76

${ }^{4}$ Muhammad ibn Abd al-Rahman al-Sakhawi, Fatah al-Maghaithmaktba alsunnah.misar,1424AHvol:3,p.299.

${ }^{5}$ Muhammad ibn Ahmad al-Dhahabi, Seerah al-A'lam al-Nubla ', Dar alHadith, Cairo, 2006, vol. 11, p. 22. 
جلدا، ويف حديث البرهكي: مائة جلد، فقلنا له: ردنا إلى الأمر الأول" (6) يقول الإمام الثاطبي عليه الرحمة (454هـ):

"ومدار الغلط في هذا الفصل إنما هو على حرف إن واحد، وهو الجهل بمقاصد الشرع، وعدم ضم أطرافه بعضها ببعض؛ فإن مأخذ الأدلة عند الأئمة الراسخين إنما هو على أن تؤخذ الشريعة كالصورة الواحدة بحسب الوبر

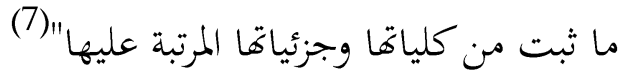

$$
\begin{aligned}
& \text { يقول الخطيب البغدادي عليه الرحمة (463هـ) : }
\end{aligned}
$$$$
\text { "قل ما يتمهر في علم الحديث ويقف على غوامضه ويستثير الخفي من المن }
$$$$
\text { فوائده إلا من جمع متفرقه وألف متشتته وضم بعضه إلى بعض واشتغل }
$$$$
\text { بتصنيف أبوابه وترتيب أصنافه" (8) }
$$

$$
\text { يقول الحافظ ابن الحجر العسقلالي عليه الرحمة (852هـ) : }
$$

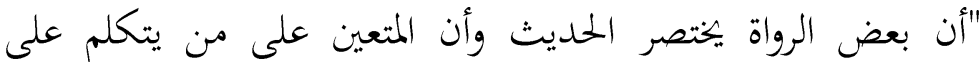

الأحاديث أن يجمع طرقها تم يجمع ألفاظ المتون إذا صحت الطرق

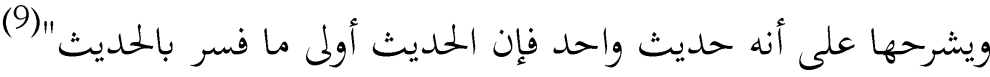

$$
\begin{aligned}
& \text { المراحل التدوينية في متون الحديث } \\
& \text { يمكن تقسيم تدوين الحديث النبوي إلى أربع مراحل: }
\end{aligned}
$$

${ }^{6}$ Ali al-Khatib, Istoria Bagdadului, Dar al-Gharb al-Islami, Beirut, 2002, vol. 4 , p. 5

${ }^{7}$ Ibrahim ibn Musa al-Shatibi, Al-Etesam, Dar Ibn Affan, Arabia Saudită, $1412 \mathrm{AH}$, p. 311

${ }^{8}$ Al-Khatib Al-Baghdadi, Al-Jami 'Lakhlaq Al-Rawi wa Adab Al-Sami, vol. 2, p. 280

${ }^{9}$ Ahmad ibn Ali ibn Hajar, Fateh al-Bari, Dar al-Ma'rifah, Beirut, 1379 AH, vol. 6, p. 475 
المرحلة الأولى : اندراج المتون بأسنا د ها :

أمثلتها من كتب الأحاديث الشهيرة :الجامع الصحيح للبخاري ، الجامع الصحيح

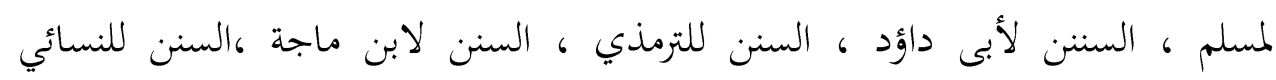

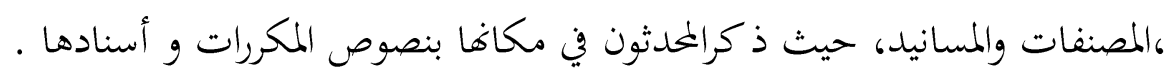
المرحلة الثانية : كتب مختلفة تجمع معا نص الحديث

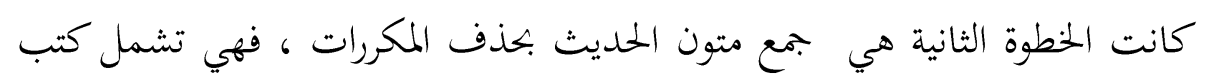

$$
\begin{aligned}
& \text { > مع الجوامع : } \\
& \text { > }
\end{aligned}
$$

$$
\text { لإبن معاوية العبدري (535هـ) }
$$

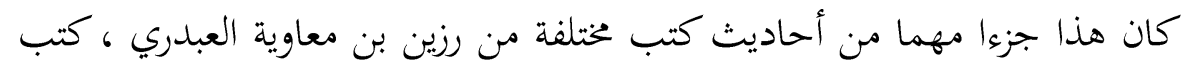

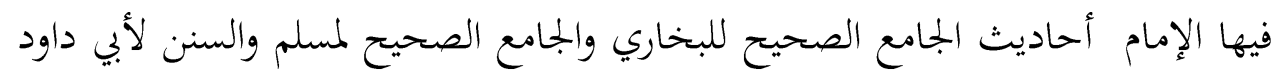

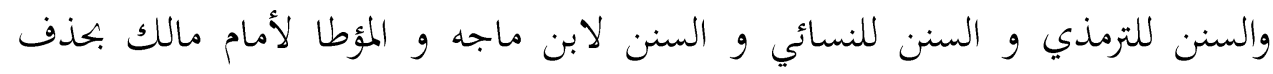

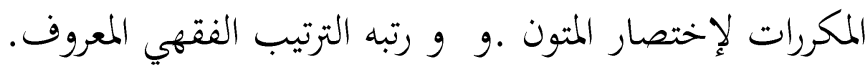

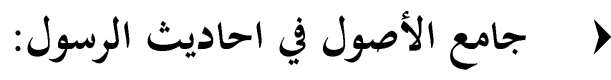

لأبي سعادات مبارك بن مُحمَّ الشيباني بمعروف لابن الاثير الجزري عليه الرحمة

يجتوي هذا الكتاب على 15 بجلدات ، جمعت فيها 9523 حديثا. أصل هذا

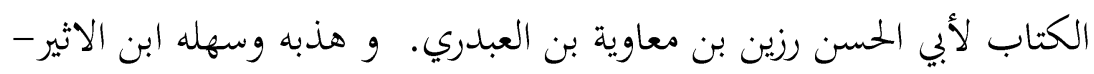
। إمع السنن والمسانيد:

لحافظ اسمعيل بن كثير القرشي الدمشقي عليه الرحمة (م774هـ

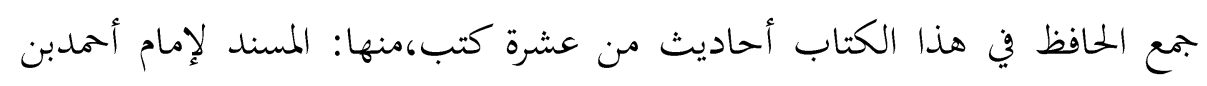


دراسة اختصاصية للصور القديمة والحديثة لجمع وتدوين متون الحديث

حنبل، الجامع الصحيح للبخاري والجامع الصحيح لمسلم والسنن لأبي داود والسنن

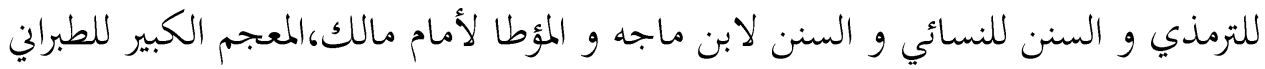

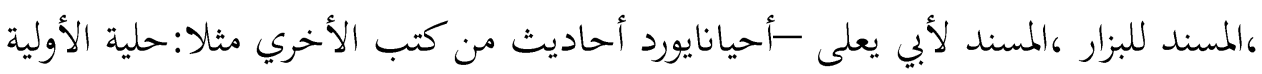

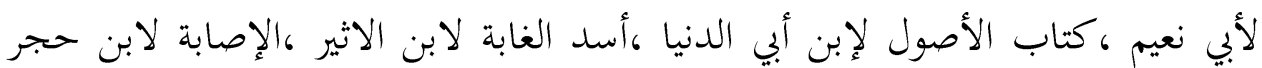

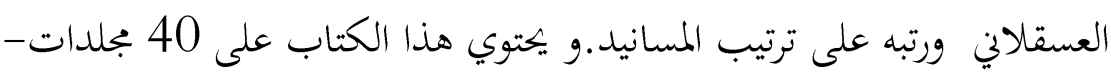

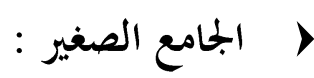
هذا الكتاب عبارة عن مجموعة تضم حافظ جلال الدين أبو الفضل بن أبي بكر بن

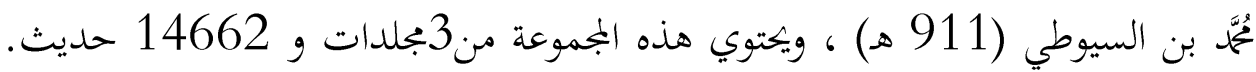

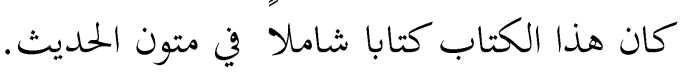

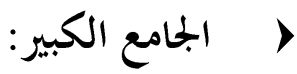
أعد هذا الكتاب أيضا الإمام السيوطي ، وعدد أحاديثه هو 46624 ، 462 ، وفي هذا

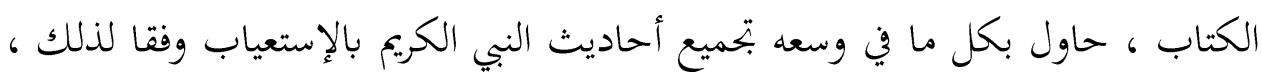

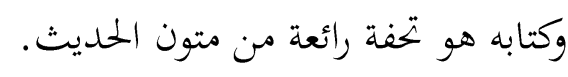
> > > بنز العمال في سنن الأقوال والأفعال:

لعلي بن حسام الدين عبد الملك بن قاضي خان بشهير متقي الهندي (975هـ)

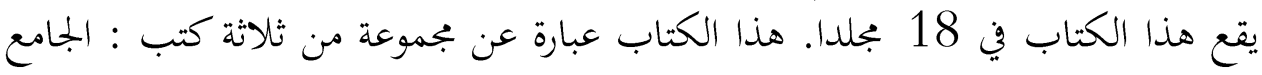

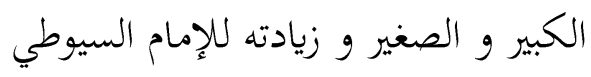

المرحلة الثالثة:جمع متون الحديث في مكان واحد محدودة :

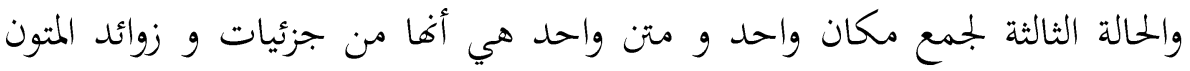

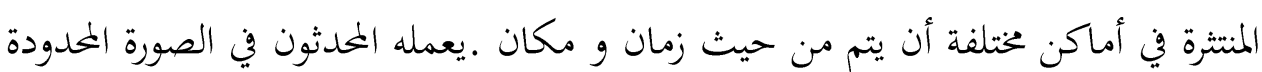
لإفادته.

ذكر الالباني في متن الحديث : 
دراسة اختصاصية للصور القديمة والحديثة لجمع وتدوين متون الحديث

"إن ملك الموت كان يأتي الناس عيانا، حتى أتى موسى عليه السلام، فقال له: أجب

ربك، قال: فلطم موسى عليه السلام، عين ملك الموت ففقأها، فرجع الملك إلى الله تعالى،

فقال: [يا رب!] إنك أرسلتني إلى عبد لك لايريد الموت، وقد فقأ عيني، [ولولا كرامته

عليك لشققت عليه] . قال: فرد الله إليه عينه، وقال: ارجع إلى عبدي فقل: الحياة تريد؟ فإن كنت تريد الحياة؛ فضع يدك على متن ثور، فما توارت يدك من شعرة؛ فإنك تعيش هما سنة، قال: [أي رب!] ثم مه؟ قال: ثم تموت، قال: فالآن من قريب، رب! أمتني من الأرض المقدسة رمية بحجر! [قال: فشمه شمة فقبض روحه، قال: فجاء بعد ذلك إلى

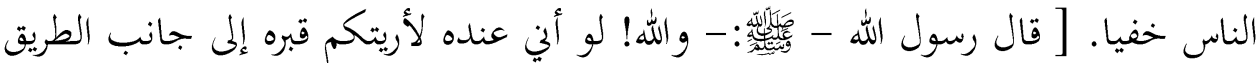

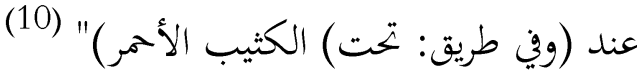

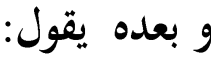

"هذا الحديث من الأحاديث الصحيحة المشهورة التي أخرجها الشيخان من طرق

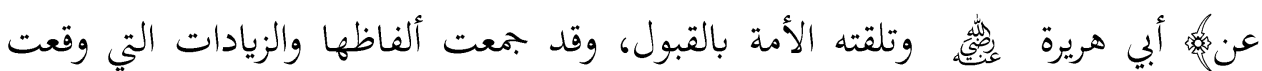
فيهاوسقتها لك سياقا واحدا كما ترى؛ لتأخذالقصة كاملة بجميع فوائدها المتفرقة في بطون مصادرها، الأمر الذي يساعدك على فهمها فهما صحيحا، لا إشكال فيه ولا شبهة، فتسلم لقول رسول اللهالأولى: عن طاوس عن أبي هريرة: أخرجه الشيخان وغيرها، وعندهما الزيادة الثالثة، وهي الطريق المشار إليهاي آخر الحديث. الثانية: عن همام عنه. أخرجاه أيضا وغيرها، والسياق لمسلم، وهو أتم. الثالثة: عن عمار بن أبي عمار قال: سمعت أبا هريرة يقول... أخرجه أحمد، وابن جرير الطبري في "التاريخ " إسناده صحيح،وهو الطريق المشار إليه في أول الحديث، وفيه

${ }^{10}$ Muhammad Nasir al-Din al-Albani, Seria de haditi autentici, Maktab al-Ma'arif lilnushar waltozee, Riyadh, Sun, vol. 7, p. 826, număr Hadith: 3279 
دراسة اختصاصية للصور القديمة والحديثة لجمع وتدوين متون الحديث

كل الزيادات إلا الثالثة" (11)
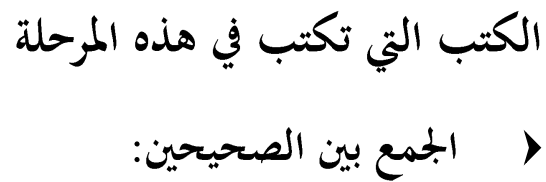

$$
\text { لأبي عبدالله عُمَّمَ بن أبي نصر فتوح ابن عبدالله الحميدي (811 هـ). }
$$

في هذا الكتاب قام الإمام بصنع عُمَّمَ بن إسماعيل البخاري (256 هـ) ومسلم بن لن

الحجاج (261 هـ) -نقل الإمام في هذا الكتاب أحاديث المشتركة التي يورد في

الصحيحين بتخطيط اختياري.

$$
\text { المحقق علي حسين يكتب عن منهجه: }
$$

"ومنهاج أبى عبدالله فن جمع المتون المتقاربة يحذف كنه كثيرا من الأحاديث

الملكررة أو المتقاربة الألفاظ ،التى لم ير فيها زيادة تستحق التنبيه كما جمله

هذا الملك على أن يجمع أحاديث طويلة جدا في مكان واحد: كحديث

السقيفة،و حديث اعتزال النبنساء، وحديث جابر والجمل ،وحديث

عائشة في الحج والحيضة،وحديث الإفك، وحديث الهجرة وغيرها منا شغل

كل حديث منها بضع صفحات .وإذا كان الغرض الرئيس للكتاب

والمؤلف جمع الصحيحين و ترتيبما، وهذا عمل ليس باليسير،وفيه جهد

كبير في تجميع الروايات و ترتيبها وعرضها إلا أن للحميدى فن الكتاب

عملا وجهوادا كثيرة ولم يتوقف عند ما ذكرناه: فهويورد رواية للحديث ثم

يقارها بسائر الروايات وبيين ما بينها من زيادات أو اختلافات أو مشابهة

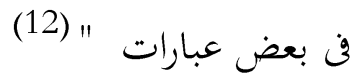

${ }^{11}$ Al-Albani, silsla ahadith alshiha, Vol 7, P. 826, Număr Hadith: 3279

${ }^{12}$ Muhammad ibn Fatuh al-Hamidi,aljmul shihan,muqadma lilDr. Ali Hussein, Dar Ibn Hazm, Beirut, 1423 AH, pp. 14-15 
دراسة اختصاصية للصور القديمة والحديثة لجمع وتدوين متون الحديث

كانت الفكرة الأولى في الإعداد الاختياري ، والتي تم جمعها متون أحاديث الجامع

$$
\text { مثلاً: }
$$

"عن عبد الله بن أبي قتادة عن أبيه قال: قال رسول الله صلى الله

عليه وسلم: إذا أقيمت الصلاة فلا تقوموا حتى تروبن (13) وأخرجه مسلم

أيضا من حديث أبي سلمة عن أبي قتادة بمثله وفي رواية إسحاق بن

إبراهيم:حتى تروين قدخرجت (14)وهوعند البخاري(15)في حديث شيبان

وعلي بن المبارك: وعليكم السكينة إإذا أقيمت الصلاة ، فلا تأتوها

تسعون، وأتوها تمشون، عليكم السكينة، فما أدركتم فصلوا، وما فاتكم

فأتموا《" (16)

في الكتاب المذكور أعلاه ، نقل الإمام الأحاديث فقط التي اتفق فيها البخاري

والمسلم ، وقد أعتمد في ترتيب وضع المتون أثناء تقديمها ، ولكن يشيرون الفاظ أحاديث الجامع البخاري و مسلم حين يضع في محله-كان هذا العمل بتميع أحاديث المشتركة من الكتابين في متن واحد جديدا.

>

لأبي عبدالله يُمَّمُ بن فرج المالكي بشهير ابن اللطلاع (497 هـ) ،

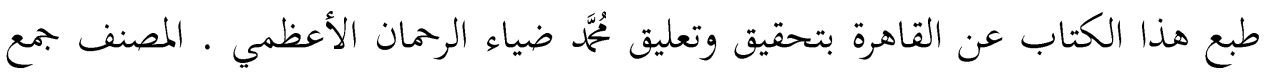

${ }^{13}$ Muhammad ibn Isma'il Bukhari, Al-Jami 'al-Sahih, Kitab al-Adhan, Dar Tawq al-Najjat, , Beirut, 1422 AH, număr Hadith: 637

${ }^{14}$ Muslim,kitabulmsajid wamwazeslat,dar ihyya altoras islami, Beirut, număr Hadith: 604

${ }^{15}$ Al-Bukhari, Al-Jami 'Al-Sahih, Kitab Al-Jumu'ah, Hadith No. 909

${ }^{16}$ Al-Hamidi, Al-Jum'a Bin Al-Sahihin, vol. 1, p. 454 
دراسة اختصاصية للصور القديمة والحديثة لجمع وتدوين متون الحديث

فيه متون أحاديث النبي التي تتعلق بقضايا النبي المختلفة و ضم زيادات الأخبار في مكان واحد بحيث اختيار الزمان و المكان صورة كاملة، وكان أول عمل من هذا النوع ، لكن فيه تفاصيل الفروع الرائعة لم تكن مرئية تماما ، وقد جمع المؤلف فيه متون منتثرة من الكتب الأخري في متن واحد. على الرغم هذه من أن تسلسلها مصحوب أيضا بواقعة ، إلا أن المؤلف يذكر مظنات الأخبار حين يضع العبارة في محلها مثلا:

" في الموطأ والبخاري والنسائي عن الزهري: أن سهل بن سعد الساعدي أخبرهم: أن عويمر العجلاين جاء إلى عاصم بن عدي الأنصاري فقال له: أرأيت رجلا وجد مع امرأته رجلا أيقتله فتقتلونه أم كيف يفعل؟ سل لي يا عاصم عن ذلك رسول الله صلى الله عليه وسلم، فسأل عن ذلك

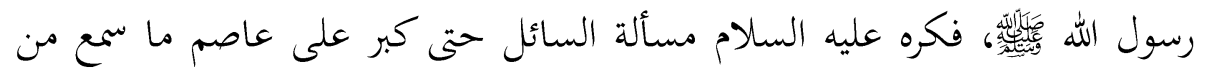

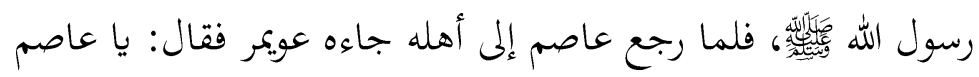

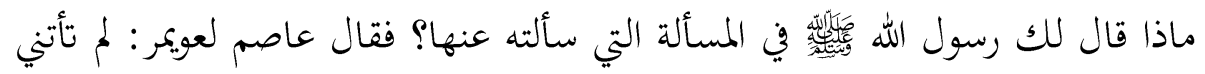
بخير قد كره رسول الله

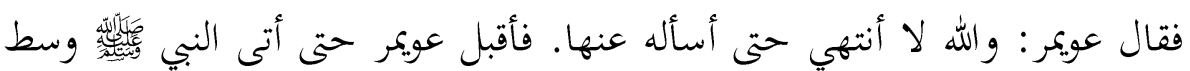

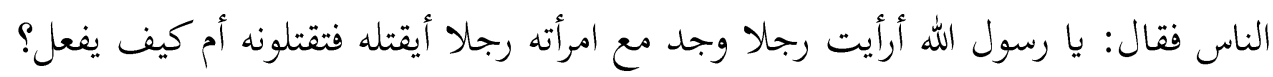
فقال رسول الله

وين البخاري: 》اقد قضى الله فيك وفي امرأتك فاذهب فأت بها《قال سهل: فتلاعنا،

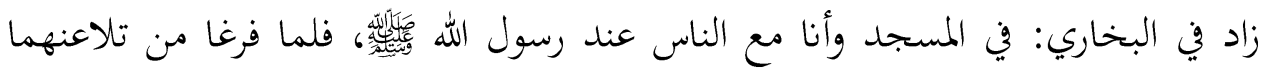
قال عويمر: كذبت عليها يا رسول الله إن أمسكتها، فطلقها ثلاثا قبل أن يأمره النبي صلى الله عليه وسلم. قال مالك: قال ابن شهاب: فكانت تلك بعد سنة المتلاعنين" (17)

${ }^{17}$ Al-Bukhari, Al-Jami 'Al-Sahih, kitabultlaq, Hadith No. 5259. 
قال ابن شهاب: وفي البخاري وكان ابنها يدعى بها، ثم جرت السنة في ميراثه أنه يرثها

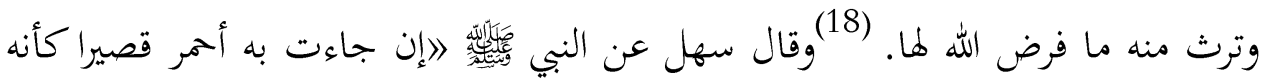
وحرة فلا أراها إلا قد صدقت وكذب عليها، وإن جاءت به أسود أعين ذا أليتين فلا أراها

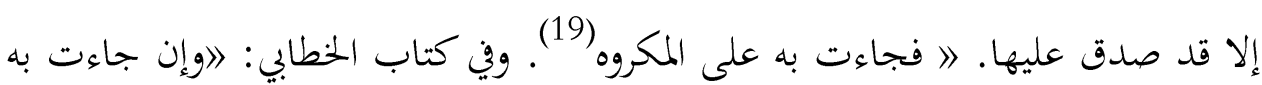

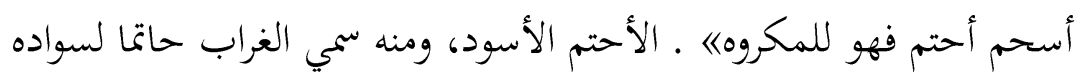

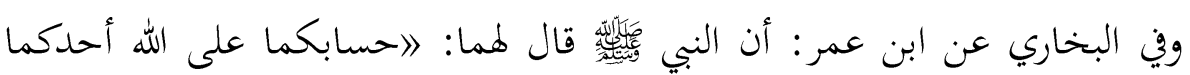

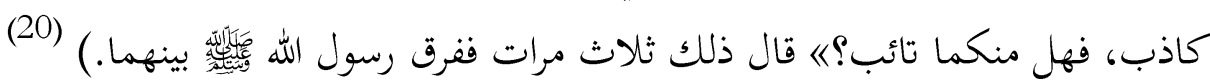

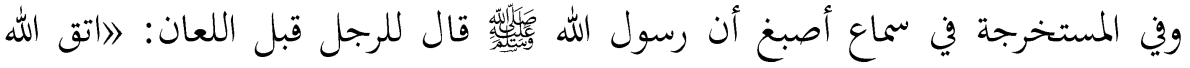

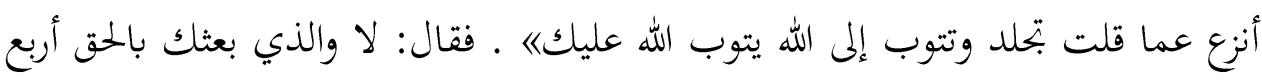

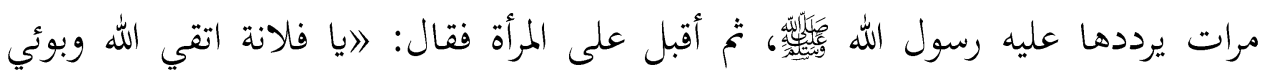

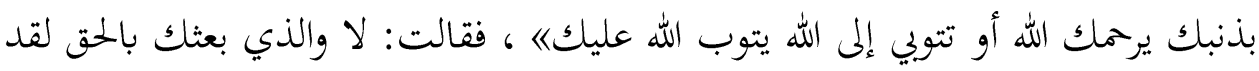

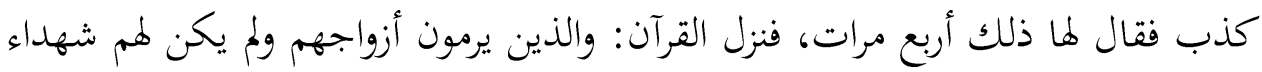

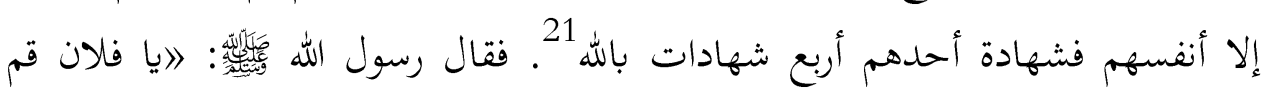

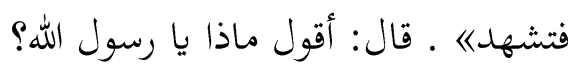

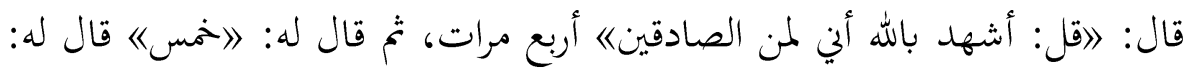

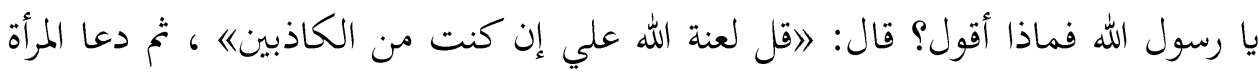

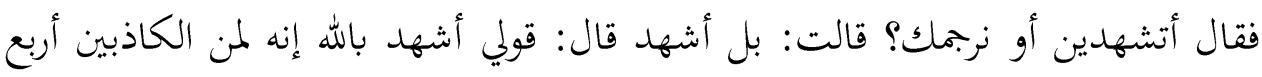

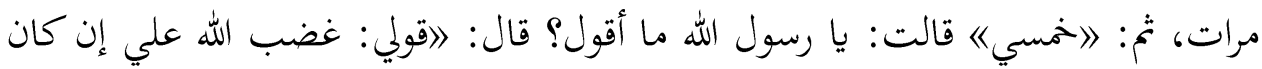

${ }^{18}$ Al-Bukhari, Al-Jami 'Al-Sahih, Kitab Tafsir Al-Quran,babul khamsa:inna lantulah alyhe in kana mnal kazbeenHadith: 4746 ${ }^{19}$ ayzun, Kitab al-Talaq, Bab al-Tala'een fi al-Masjid, Hadith No.5309 ${ }^{20}$ ayzun, Kitab al-Talaq, Bab al-Qul al-Imam al-Mutla'eenin ahdkma kazab, Hadith No. 5312.

${ }^{21}$ Al-noor, 6:24 
من الصادقينه ، ففعلت فقال رسول الله له

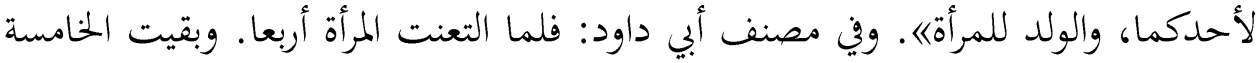

قيل لها: اتقي الله هذه الموجبة توجب عليك العذاب، فتلكأت ساعة ثم قالت: والله لا

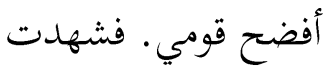

الخامسة ففرق رسول الله بينهما وقضى رسول الله

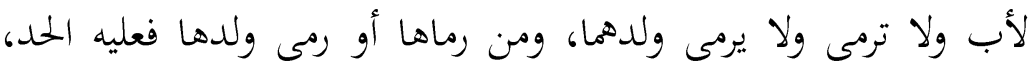

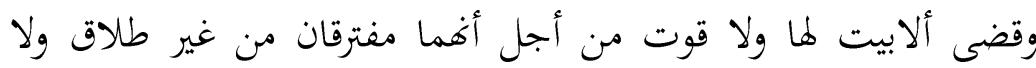

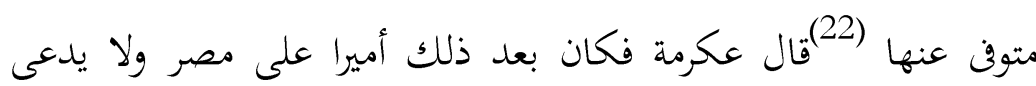

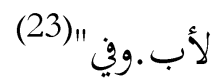

المرحلة الرابعة :الترتيب الإختياري والإجتهادي بإنضمام متون الحديث

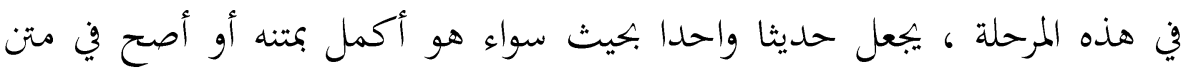

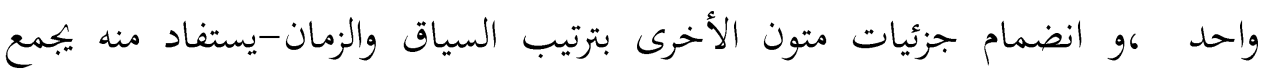

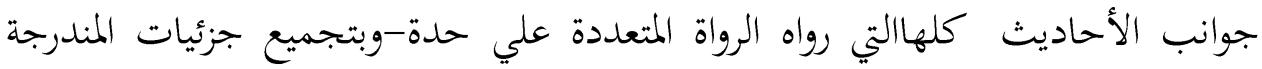
يعمل الإستنباط الصحيح في أخذ المسائل.

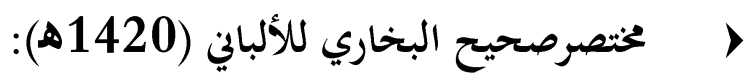

أنه أول شخص الذي أختر صورة المشكلة بترتيب الإجتهادي في بتميع المتون ولا

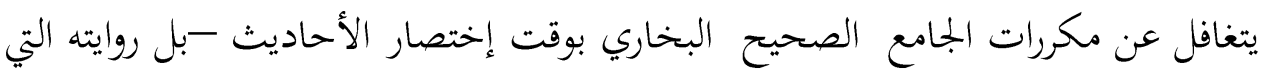

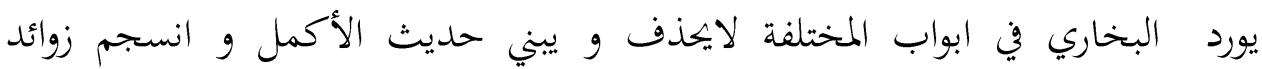

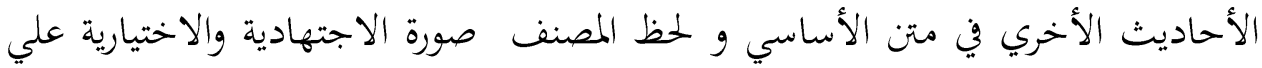
عمل الترتيب -وجعل النصوص اختيارية في متن واحد و تشكيل من عبارات متعددة في

${ }^{22}$ Abu Dawud, Al-Sunan, Kitab al-Talaaq, Bab fi al-Laan, Hadith No;2256

${ }^{23} \mathrm{Al}$-Hamidi, Al-Jum'a Bin Al-Sahihin, p. 80 
صورة محكمة بحيث السياق والزمان. قام بهذا العمل الألباني ويقول فيه:

حذفت أسانيد أحاديثه كلها، ولم أبق منها إلا اسم الصحابي راوي الحديث عن النبي

-

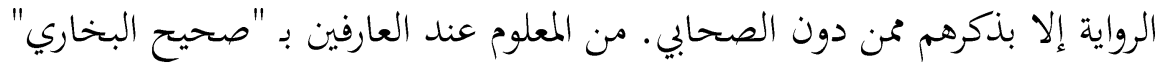

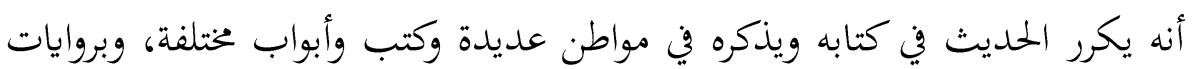

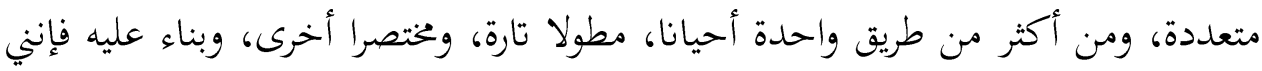

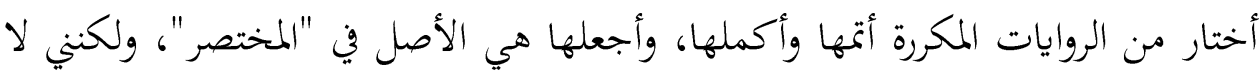

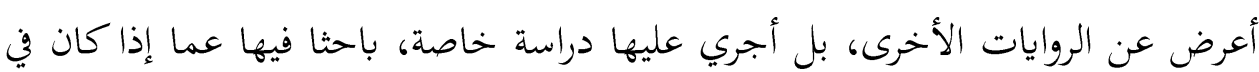

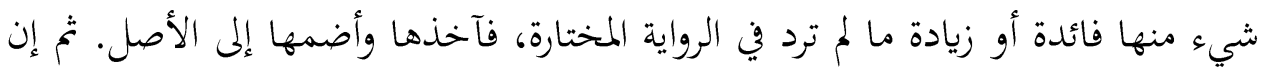
الضم المذكور يكون على صورة من صورتين:

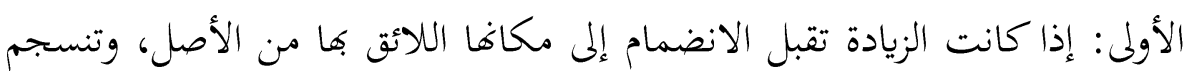

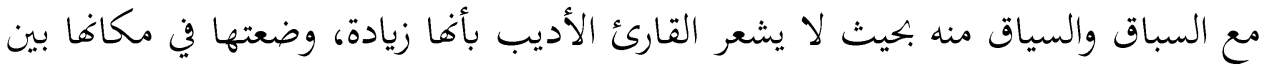
قوسين معقوفين" (24) معناف والسيات يعرض مثال الترتيب الذي نقل الألباني في مختصره :

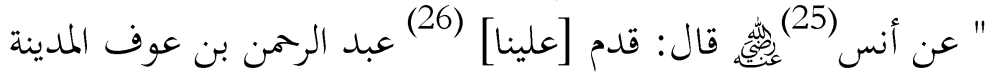

$$
\begin{aligned}
& \text { (وفي رواية: لما قدموا المدينة، نزل المهاجرون على الأنصار،فنزل عبد الرممن }
\end{aligned}
$$

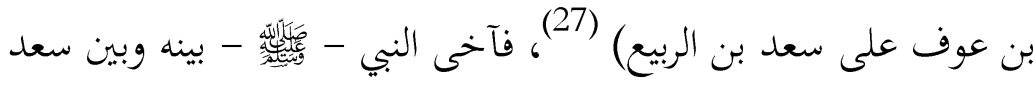

${ }^{24}$ Muhammad Nasir al-Din al-Albani, Sahih al-Bukhari, Maktab al-Ma'arif, Riyadh, prima ediție, 2002, vol. 1, p. 7

${ }^{25}$ Al-Bukhari, Al-Jami 'Al-Sahih, Kitab Al-Bayou',bab ma ja fi qolilahi tala fiza qzyta alslat, Hadith No. 2049

${ }^{26}$ ayzun, Kitab al-Manaqib, bab ikha ul nbyya banaul muhajreen wal ansar Hadith: 3781

${ }^{27}$ ayzun, Kitab al-Nikah, Bab al-Walimah walu Bashaat, Hadith No.5167 


$$
\begin{aligned}
& \text { بن الربيع الأنصاري، وكان سعد ذا غنى [وعنده امرأتان] (28) فقال لعبد }
\end{aligned}
$$

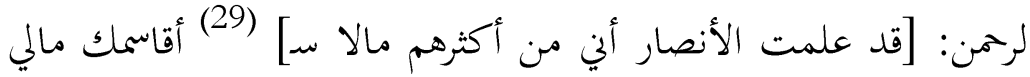

$$
\begin{aligned}
& \text { نصفين، وأزوجك (وفي رواية: ولي امرأتان، فانظر أعجبهما إليك، } \\
& \text { فأطلقها، حتى إذا حلت تزوجتها) (30)قال: بارك الله لك في أهلك ومالك وروتك }
\end{aligned}
$$

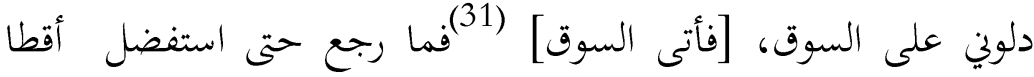

$$
\begin{aligned}
& \text { وسمنا،فأتى به أهل منزله، فمكثنا يسيرا،أو ما شاء الله، فجاء، (وفي رواية: }
\end{aligned}
$$

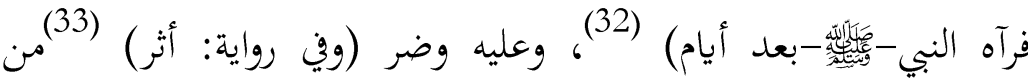

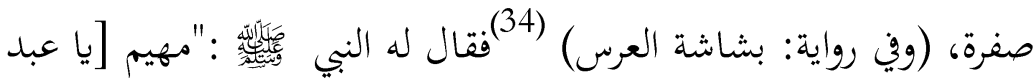

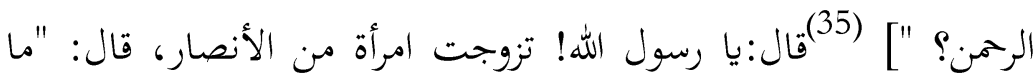

$$
\begin{aligned}
& \text { سقت إليها؟ "قال: [زنة] (36)نواة من ذهب، أو وزن نواة من ذهب، } \\
& \text { قال: " [بارك الله لك] (37) أولم ولو بشاة" (38) }
\end{aligned}
$$

${ }^{28}$ Al-Bukhari, Al-Jami 'Al-Sahih, Kitab Al-Nikah, Bab qolarjli liakhihi unzur ay zojti hutta unzl lka anha, Hadith No. 5072

${ }^{29}$ ayzun, Kitab al-Manaqib, bab ikha ul nbyya banaul muhajreen wal ansar, Hadith: 3781

${ }^{30}$ ayzun

${ }^{31}$ ayzun, Kitab al-Nikah, Bab Bab qolarjli liakhihi unzur ay zojti hutta unzl lka anha, Hadith No. 5072

${ }^{32}$ Ayzun, Kitab al-Manaqib, Hadith: 3937

${ }^{33}$ Al-Bukhari, Al-Jami 'Al-Sahih, Kitab Al-Bayou', bab ma ja fi qolilahi tala fiza qzyta alslat, Hadith No. 2048

${ }^{34}$ ayzun, Kitab al-Nikah, bab fi qol lilah tala wa ato ansa sdaqathinna nhlttun Hadith No. 5148

${ }^{35}$ ayzun, Kitab al-Nikah, Bab al-Qawl al-Rajl Lakhiyah Anzar e Zujati Hati Anzal Lak Anha, Hadith No. 5072

${ }^{36}$ Al-Bukhari, Al-Jami 'Al-Sahih, Kitab Al-Bayou', bab ma ja fi qolilahi tala fiza qzyta alslat, Hadith No. 2048

37 ayzun, Kitab al-Manaqib, Hadith: 3937

${ }^{38}$ Al-Albani, Sahih Al-Bukhari, Kitab Al-Bayou ', Hadith No. 966 


\section{> الموسوعة القضايةمن موسوعة الأحكام الصادرة من المحاكم الإسلامية :}

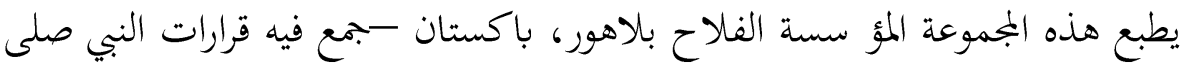

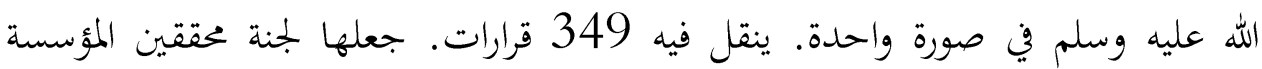

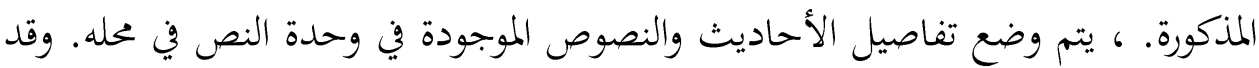

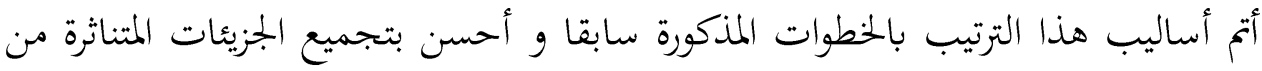
متون الأحاديث.

تشتمل هذه المجموعةعلي قرارات النبي التي قضى فيها في أوقات مختلفة لهذا راجعت

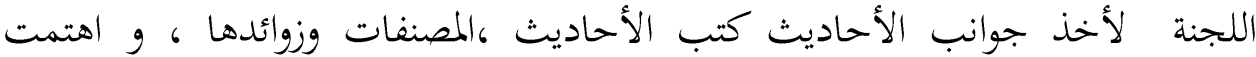

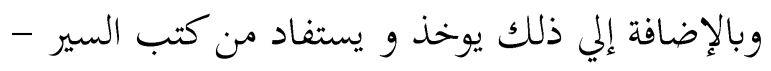

مثلا:

\section{حكم رسول الله فى الحد على المريض:}

أبي أمامة بن سهل بن حنيف (39) أن بعض أصحب رسول الله مأه من الأنصار إنه

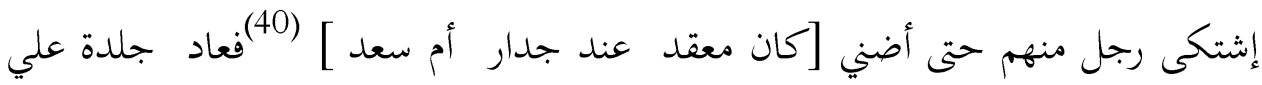
عظم فدخلت عليه جارية لبعضهم [أمة من بني ساعة ]

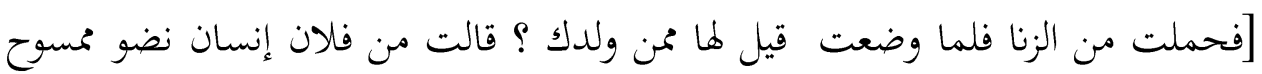

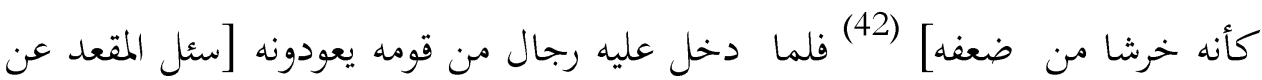
ذلك فاعترف و ] (43) أخبر هم بذلك [فنقال صدقت هو مني ]

${ }^{39}$ Abu Dawud, Al-Sunan, Kitab al-Hudood, Bab fi Iqamah al- Hadd alMariz, Hadith No.: 4472

${ }^{40}$ Al-Dar Qatani, Al-Sunan, Kitab Al-Hudood wa Al-Diyat, Hadith No. 3157

41 ayzun

42 ayzun

43 ayzun

${ }^{44}$ Bayhaqi, Al-Sunan Al-Kubra, vol. 4, p. 94 
رسول الله فإني قد وقعت علي جارية دخلت علي فذكر و ا ذلك لرسول الله صلى الله عليه وآله وسلم [فرفع شأنه سعدبن عبادة ]

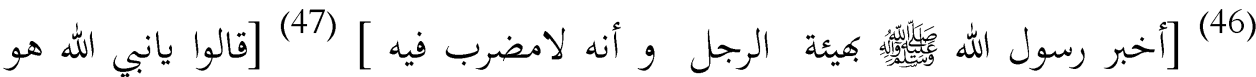

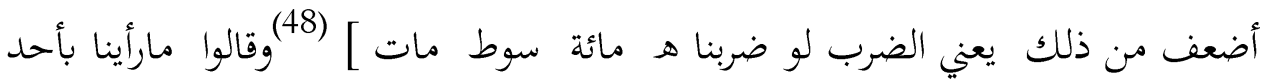
من الناس من الضر مثل الذي هو به لو حملناه إليك لتفسخت عظامه ما هو إلا جلد

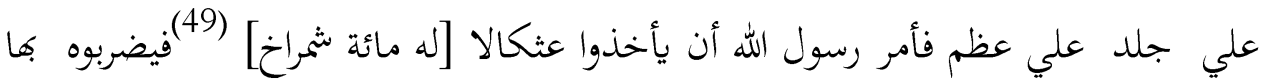
ضربة واحدة" (50)

يوضح التفسير المندرجات المذكورة أعلاها أهمية تدوين الفني في متون الحديث. لابد

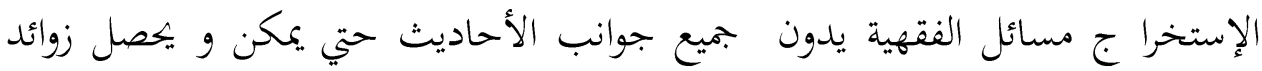

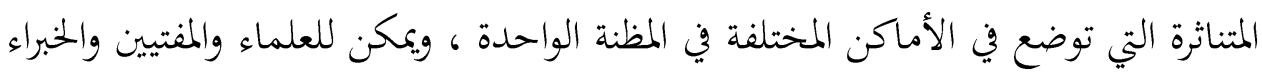

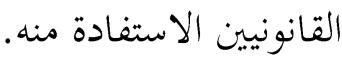

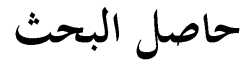

إن الحكم كاف للنتائج الصحيحة والصحيحة للشريعة ، بحيث يكون من الضروري جمع الجزء الكامل من نص الأحاديث في مكان واحد حتى تأتي كل الكلمات والجوانب في هذا لأنا

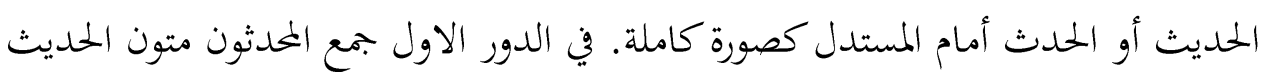

\section{${ }^{45}$ ayzun}

${ }^{46}$ Ibn Majah, Al-Sunan, Kitab al-Hudood, Bab al-Kabeer wa al-Mariz yajib alayh al-hadd, Hadith No. 2574

${ }^{47}$ Bayhaqi, Al-Sunan Al-Kubra, vol. 4, p. 94

${ }^{48} \mathrm{Ibn}$ Majah, Al-Sunan, Kitab al-Hudood, Bab al-Kabeer wa al-Mariz wa yajib alayh al-hadd, Hadith No. 2574

${ }^{49}$ ayzun, Kitab al-Hudood, Bab al-Kabeer wa al-Mari waz yajb alayh alHud, Hadith No: 2574

${ }^{50}$ Almosoa tulqzaiyya min mosoa alahkam alsadira minalmhakim alislamia,mosisa a Al-Falah, Lahore, Sun, 63-64 
The Scholar Islamic Academic Research Journal

Vol. 6, No. 1 || Janurary -June2020 ||P.50-66

https://doi.org/10.29370/siarj/issue10ararabic3

بالأسنادو يكتبون الكتب علي هذا الفن - وفي الدور الثاني يجمع متون الحديث بدون

الأسناد و في المرحلة الثالثة يتم أجزاء متون الحديث علي نطاق محدد ، وفي المرحلة الرابعة

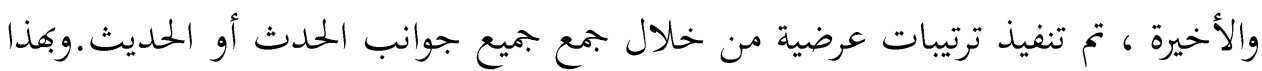

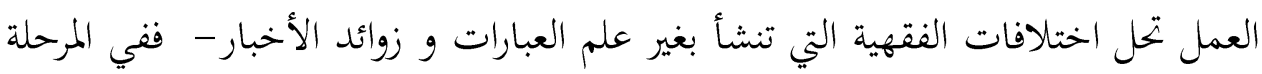

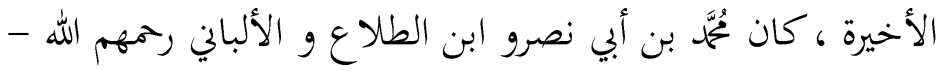

